\title{
Hybrid positron emission tomography and magnetic resonance imaging in carotid atherosclerosis: Not ready for prime time?
}

\author{
Ahmed Haider, PhD, ${ }^{\mathrm{a}, \mathrm{b}}$ Susan Bengs, PhD, ${ }^{\mathrm{a}, \mathrm{b}}$ Catherine Gebhard, MD, PhD, ${ }^{\mathrm{a}, \mathrm{b}}$ \\ and Michael Fiechter, MD, PhD ${ }^{\mathrm{a}, \mathrm{b}, \mathrm{c}}$ \\ a Department of Nuclear Medicine, University Hospital Zurich, Zurich, Switzerland \\ b Center for Molecular Cardiology, University of Zurich, Schlieren, Switzerland \\ c Swiss Paraplegic Center, Nottwil, Switzerland
}

Received Oct 16, 2020; accepted Oct 16, 2020

doi: $10.1007 / \mathrm{s} 12350-020-02426-4$

See related article, https://doi.org/10.10 07/s12350-020-02400-0.

Carotid atherosclerosis remains a major cause of cerebrovascular insults. ${ }^{1,2}$ Although anatomical assessment of luminal narrowing is frequently performed in clinical routine, it does not reliably identify high-risk culprit lesions that are characterized by morphological features such as a thin fibrous cap, a large lipid-rich necrotic core, neovascularization, and intraplaque hemorrhage. ${ }^{3}$ Given the high spatial resolution of magnetic resonance imaging (MRI), which provides an excellent soft tissue contrast, MRI is perfectly suited to assess the abovementioned morphological carotid plaque features. ${ }^{4}$ Nonetheless, culprit lesions are not only characterized by a detrimental morphology, but are frequently accompanied by active inflammation and microcalcification processes. ${ }^{5}$ As such, functional imaging with positron emission tomography (PET) has tackled a

Funding CG was supported by grants from the Swiss National Science Foundation (SNSF), the Olga Mayenfisch Foundation, Switzerland, the OPO Foundation, Switzerland, the Novartis Foundation, Switzerland, the Swissheart Foundation, the Helmut Horten Foundation, Switzerland, the EMDO Foundation, the Iten-Kohaut Foundation, Switzerland, the University Hospital Zurich Foundation, and the LOOP, Zurich. AH was supported by the University of Zurich (UZH) Foundation. MF was supported by the Swiss Paraplegic Center. SB was supported by the Swissheart Foundation and the UZH Foundation.

Reprint requests: Michael Fiechter, MD, PhD, Department of Nuclear Medicine, University Hospital Zurich, 8091 Zurich, Switzerland; michael.fiechter@usz.ch

J Nucl Cardiol 2022;29:3458-60.

$1071-3581 / \$ 34.00$

Copyright (c) 2020 American Society of Nuclear Cardiology. longstanding issue by providing a highly sensitive and non-invasive detection method for activated macrophages, which constitute a hallmark of atherosclerosis. ${ }^{6}$ PET tracers that have been harnessed for vascular macrophage imaging mainly include ${ }^{18}$ F-fluorodeoxyglucose $\left({ }^{18} \mathrm{~F}-\mathrm{FDG}\right)$, somatostatin receptortargeted and translocator protein (TSPO)-directed probes. ${ }^{6}$ Further, microcalcification processes can be visualized by ${ }^{18} \mathrm{~F}$-sodium fluoride $\left({ }^{18} \mathrm{~F}-\mathrm{NaF}\right)$ PET due to the inherent ability of fluoride ions to react with hydroxyapatite crystals. ${ }^{7}$ Considering the complementing properties of PET and MRI, it is not surprising that hybrid PET/MRI systems have been developed and recently introduced to nuclear medicine facilities-with high expectations.

In this issue of the Journal of Nuclear Cardiology, Mechtouff et al. report on an exploratory study assessing the potential of hybrid PET/MRI with ${ }^{18} \mathrm{~F}-\mathrm{NaF}$ to provide information on plaque morphology and the extent of microcalcification in the carotid arteries. The authors included a total of 12 patients with carotid stenosis and found that ${ }^{18} \mathrm{~F}-\mathrm{NaF}$ uptake was higher in culprit vs. nonculprit carotid plaques. Although the application of ${ }^{18} \mathrm{~F}$ $\mathrm{NaF}$ PET for carotid plaque imaging was previously established by hybrid PET/computed tomography (CT) ${ }^{8-10}$ the fact that these findings can be reproduced with PET/MRI is particularly encouraging due to (1) the advantages of MRI over CT including a significantly better soft tissue contrast and the absence of ionizing radiation, and (2) the technical challenges posed by MRI-based attenuation correction. Importantly, the specificity of the radioactive signal and its accuracy were further supported by the positive correlation between ${ }^{18} \mathrm{~F}$-fluoride plaque uptake and calcium plaque volume, indicating that the higher uptake observed in culprit lesions was indeed driven by microcalcification 
processes. However, the relatively high proportion of incomplete or uninterpretable imaging data in the study by Mechtouff et al. underscores an important challenge of contemporary hybrid PET/MRI that is of technical nature, namely, compatibility issues between the magnetic field and essential PET scanner components. The latter hampers axial resolution and results in longer acquisition times for the patient. Moreover, non-compatibility of MRI with metallic implants can reduce the number of patients eligible for PET/MRI scans. Despite these challenges, the advent of combined PET/MRI presents an invaluable opportunity and technical refinements are currently ongoing.

Although the study by Mechtouff et al. provides several interesting insights, its exploratory nature along with the relatively low sample size, precludes the comparison of ${ }^{18} \mathrm{~F}-\mathrm{NaF}$ PET findings with morphological observations on MRI. Consequently, although PET findings seemed decoupled from MRI in their study, the authors correctly state that their observations are to be interpreted with caution and need to be validated in larger trials. In particular, the fact that MRI findings were not in agreement with histological results is a major limitation of their study and underlines the need for studies with larger sample sizes to increase statistical power.

Another important limitation of ${ }^{18} \mathrm{~F}-\mathrm{NaF}$ PET is the unspecific accumulation of ${ }^{18} \mathrm{~F}$-fluoride ions within the bone matrix. In fact, when carotid arteries are assessed, data analysis is complicated by spillover from the spine. To overcome this limitation, mathematical models that correct for partial volume effects are typically applied during data reconstruction or image analysis. Nevertheless, in the latter case, data accuracy is only as good as the models applied for correction, constituting a potential source of residual uncertainty. Considering this spillover issue, along with the notion that microcalcification is inflammation-driven, the question arises whether ${ }^{18} \mathrm{~F}-\mathrm{NaF}$ is superior to ${ }^{18} \mathrm{~F}$-FDG PET for functional plaque assessment in carotid arteries. The latter is the current gold standard for non-invasive vascular inflammation imaging. Indeed, Friera et al. recently demonstrated that carotid-specific arterial inflammation can be reliably detected by hybrid ${ }^{18}$ F-FDG PET/MRI in 755 individuals with subclinical atherosclerosis that were recruited as part of the PESA (Progression of Early Subclinical Atherosclerosis) study. ${ }^{11}$ In contrast to the findings by Mechtouff et al., the PESA study unveiled that PET tracer uptake was higher in plaques with a larger lipid core as determined by MRI. It should be noted, however, that these seemingly divergent findings may be caused by the distinct baseline characteristics of the study cohorts: While Mechtouff et al. included patients with symptomatic and non-symptomatic carotid stenosis, the PESA study cohort consisted of individuals with subclinical atherosclerosis.

A study reporting data from am more homogenous sample was recently published by Hacker et al. ${ }^{12}$ The authors included 34 patients with carotid plaques who underwent both PET/CT and PET/MRI with ${ }^{18}$ F-FDG for comparison. A good correlation was found for maximum standardized uptake values $\left(\mathrm{SUV}_{\max }\right)$ and target-to-blood ratios $\left(\mathrm{TBR}_{\max }\right)$ between PET/CT and PET/MRI. However, due to systematic underestimation of $\mathrm{SUV}_{\max }$ and $\mathrm{TBR}_{\max }$ by PET/MRI, the use of different cut-off reference values was suggested for PET/ $\mathrm{CT}$ and PET/MRI. Notably, the authors did not disclose whether plaque morphology, as determined by MRI, was associated with tracer uptake in the carotid plaques. Thus, further PET/MRI studies with ${ }^{18} \mathrm{~F}-\mathrm{NaF}$ and ${ }^{18} \mathrm{~F}$ FDG are required to assess whether the advent of combining morphological and functional plaque assessment adds incremental prognostic value to contemporary atherosclerosis imaging.

In conclusion, despite the relatively small sample size, the study by Mechtouff et al. provides initial insights into the challenges and opportunities of PET/ MRI for atherosclerosis imaging. Given that PET/MRI is still in its infancy, such data is currently scarce-particularly with ${ }^{18} \mathrm{~F}-\mathrm{NaF}$. Future clinical trials on atherosclerotic plaque detection and classification in larger study populations are warranted to exploit the advent of hybrid PET/MRI, which may harbor enormous potential to deliver personalized cardiovascular care.

\section{Disclosure}

All authors have the following to disclose: The University Hospital of Zurich holds a research contract with GE Healthcare. $C G$ has received research grants from the Novartis Foundation, Switzerland.

\section{References}

1. Campbell BCV, De Silva DA, Macleod MR, Coutts SB, Schwamm LH, Davis SM, Donnan GA. Ischaemic stroke. Nat Rev Dis Primers 2019;5(1):70.

2. van Lammeren GW, den Ruijter HM, Vrijenhoek JE, van der Laan SW, Velema E, de Vries JP, de Kleijn DP, Vink A, de Borst GJ, Moll FL, Bots ML, Pasterkamp G. Time-dependent changes in atherosclerotic plaque composition in patients undergoing carotid surgery. Circulation 2014;129(22):2269-76.

3. Evans NR, Tarkin JM, Le EP, Sriranjan RS, Corovic A, Warburton EA, Rudd JH. Integrated cardiovascular assessment of atherosclerosis using PET/MRI. $\mathrm{Br} \quad \mathrm{J}$ Radiol 2020;93(1113):20190921.

4. Yuan C, Mitsumori LM, Ferguson MS, Polissar NL, Echelard D, Ortiz G, Small R, Davies JW, Kerwin WS, Hatsukami TS. In vivo accuracy of multispectral magnetic resonance imaging for 
identifying lipid-rich necrotic cores and intraplaque hemorrhage in advanced human carotid plaques. Circulation 2001;104(17):20516.

5. Joseph P, Tawakol A. Imaging atherosclerosis with positron emission tomography. Eur Heart J 2016;37(39):2974-80.

6. Tarkin JM, Joshi FR, Rudd JHF. PET imaging of inflammation in atherosclerosis. Nat Rev Cardiol 2014;11(8):443-57.

7. Irkle A, Vesey AT, Lewis DY, Skepper JN, Bird JL, Dweck MR, Joshi FR, Gallagher FA, Warburton EA, Bennett MR, Brindle KM, Newby DE, Rudd JH, Davenport AP. Identifying active vascular microcalcification by (18)F-sodium fluoride positron emission tomography. Nat Commun 2015;6:7495.

8. Joshi NV, Vesey AT, Williams MC, Shah AS, Calvert PA, Craighead FH, Yeoh SE, Wallace W, Salter D, Fletcher AM, van Beek EJ, Flapan AD, Uren NG, Behan MW, Cruden NL, Mills NL, Fox KA, Rudd JH, Dweck MR, Newby DE. 18F-fluoride positron emission tomography for identification of ruptured and high-risk coronary atherosclerotic plaques: A prospective clinical trial. Lancet 2014;383(9918):705-13.

9. Kitagawa T, Yamamoto H, Toshimitsu S, Sasaki K, Senoo A, Kubo Y, Tatsugami F, Awai K, Hirokawa Y, Kihara Y. (18)Fsodium fluoride positron emission tomography for molecular imaging of coronary atherosclerosis based on computed tomography analysis. Atherosclerosis 2017;263:385-92.

10. Cocker MS, Spence JD, Hammond R, Wells G, deKemp RA, Lum C, Adeeko A, Yaffe MJ, Leung E, Hill A, Nagpal S, Stotts G, Alturkustani M, Hammond L, DaSilva J, Hadizad T, Tardif JC, Beanlands RS. [(18)F]-NaF PET/CT identifies active calcification in carotid plaque. JACC Cardiovasc Imaging 2017;10(4):486-8.

11. Fernández-Friera L, Fuster V, López-Melgar B, Oliva B, SánchezGonzález J, Macías A, Pérez-Asenjo B, Zamudio D, Alonso-Farto JC, España S, Mendiguren J, Bueno H, García-Ruiz JM, Ibañez B, Fernández-Ortiz A, Sanz J. Vascular inflammation in subclinical atherosclerosis detected by hybrid PET/MRI. J Am Coll Cardiol 2019;73(12):1371-82.

12. Li X, Heber D, Rausch I, Beitzke D, Mayerhoefer ME, Rasul S, Kreissl M, Mitthauser M, Wadsak W, Hartenbach M, Haug A, Zhang X, Loewe C, Beyer T, Hacker M. Quantitative assessment of atherosclerotic plaques on (18)F-FDG PET/MRI: Comparison with a PET/CT hybrid system. Eur J Nucl Med Mol Imaging 2016;43(8):1503-12.

Publisher's Note Springer Nature remains neutral with regard to jurisdictional claims in published maps and institutional affiliations. 